\title{
VARIAÇÕES SOBRE O MESMO TEMA: REPRESENTAÇÕES CONCORRENCIAIS SOBRE GARRINCHA NA "HISTÓRIA DO RÁDIO"
}

\author{
Diano Albernaz Massarani ${ }^{1}$
}

\begin{abstract}
RESUMO: No acervo de conteúdos simbólicos produzidos sobre Garrincha destacam-se histórias que narram passagens de sua vida. Não raramente essas histórias apresentam versões com significativas diferenças, como é o caso da "história do rádio", que conta com versões que representam Garrincha como malandro e com versões que o representam como ingênuo. Neste trabalho, pretende-se por em evidência o processo de construção de diferentes versões de uma mesma história sobre Garrincha que, a despeito das divergências, são contadas por seus narradores como verdadeiras. Argumenta-se conclusivamente que a ausência de uma versão da "história do rádio" a ser tomada como referência na busca por correções possibilita aos narradores uma maior liberdade criativa e a coexistência de uma pluralidade de versões. Acrescenta-se que as singularidades existentes nas versões relacionam-se com os interesses dos narradores em construir determinadas representações sobre Garrincha e sobre os outros personagens que figuram na história.
\end{abstract}

Palavras-chave: Garrincha; representações; "história do rádio".

\section{VARIATIONS ON THE SAME THEME: COMPETITIVE REPRESENTATIONS ABOUT GARRINCHA IN THE "STORY OF THE RADIO"}

\begin{abstract}
Among the symbolic content produced on Garrincha it is possible to highlight the stories that narrate passages of his life. Quite often these stories present versions that contains significant differences, as in the case of the "radio story", which some versions show Garrincha as a trickster ("malandro") and some show him as a naïve ("ingênuo"). This study aims to understand the construction process of different versions of a same story about Garrincha that, despite divergences, are narrated as true. It is argued, conclusively, that the absence of a version of the "radio story" to be accessed as a reference, in the search for corrections, allows the narrator a greater creative freedom and enables the coexistence of diverse versions. In addition, the singularities existing in each version are related to the interests of the narrator in constructing certain types of representations on Garrincha and on the other protagonists of the story.
\end{abstract}

Keywords: Garrincha; representations; "radio story".

Garrincha, em sua irresponsabilidade amável, poderia, quem sabe?, fornecer-nos a chave de um segredo de que era possuidor e que ele mesmo não decifrava, inocente que era da origem do poder mágico e de seus músculos e pés. Divertido, espontâneo,

\footnotetext{
${ }^{1}$ Graduado em Engenharia Química pela Universidade Federal Fluminense (UFF);

Graduado em Comunicação Social - Jornalismo pela Universidade Federal Fluminense (UFF);

Mestre em Antropologia pelo Programa de Pós-Graduação em Antropologia (PPGA) da Universidade Federal Fluminense (UFF); aluno de doutorado em Antropologia do Programa de Pós-Graduação em Antropologia (PPGA) da Universidade Federal Fluminense (UFF). Contato: diano_am@yahoo.com.br
} 
inconsequente, com uma inocência que não excluía espertezas instintivas de Macunaíma - nenhum modelo seria mais adequado do que esse, para seduzir um povo que, olhando em redor, não encontrava os sérios heróis, os santos miraculosos de que necessita no dia-a-dia. A identificação da sociedade com ele fazia-se naturalmente. Garrincha não pedia nada a seus admiradores; não lhes exigia sacrifícios ou esforços mentais para admirá-lo e segui-lo, pois de resto não queria que ninguém o seguisse. Carregava nas costas um peso alegre, dispensando-nos de fazer o mesmo. (ANDRADE, 2002, p. 217-218).

Na crônica Mané e o sonho, publicada a 22 de janeiro de 1983, dois dias após o falecimento de Garrincha ${ }^{1}$, Carlos Drummond de Andrade não mede sua liberdade poética ao listar características que considera formadoras da personalidade do jogador. No trecho que abre este artigo, Garrincha é retratado como irresponsável, esperto, inocente, espontâneo, divertido e inconsequente, características estas frequentemente acionadas na produção das duas representações dominantes a seu respeito: malandro e ingênuo. À primeira vista, essas representações parecem excludentes, mas, como destaca Vogel, Garrincha surge como "uma figura paradigmática de extraordinária força e importância na galeria dos heróis da nacionalidade brasileira" (VOGEL, 1982, p. 107) justamente por ser construído como um "malandro que fazia rir os torcedores, com suas jogadas e histórias" (VOGEL, 1982, p. 106), mas cuja "ingenuidade podia ser surpreendente, a ponto de colocar em dúvida as suas capacidades intelectuais" (VOGEL, 1982, p. 107).

O acervo material e simbólico que serve de base para a produção de representações sobre Garrincha é extenso. Em um conhecido trabalho acadêmico sobre Garrincha, Leite Lopes e Maresca ressaltam a existência de "uma abundante literatura interpretativa produzida por jornalistas, mas também por escritores-cronistas de futebol, como Nelson Rodrigues, ou poetas e cronistas, como Carlos Drummond de Andrade, Vinícius de Moraes, Paulo Mendes Campos" (LEITE LOPES; MARESCA, 1992, p. 120). É neste sentido, também, que Wisnik, citando o boliviano Antezana, afirma o seguinte: "Garrincha desperta e provoca a interpretação infinita, na forma de 'digressões em torno de uma legenda', ou glosas a um conto das mil e uma noites" (WISNIK, 2008, p. 273).

Ainda acerca do acervo de conteúdos simbólicos produzidos sobre Garrincha, é possível notar uma singularidade em relação a outros personagens do campo futebolístico: há uma grande quantidade de narrativas que se propõem a contar histórias sobre sua vida dentro e fora dos gramados. Como nota Ruy Castro, autor da biografia Estrela Solitária - Um brasileiro chamado Garrincha (1996): "Poucos brasileiros tiveram mais histórias contadas a 
seu respeito que Garrincha" (CASTRO, 1995, p. 96). Condicionado por valores tidos como essenciais ao jornalismo ${ }^{2}$, Castro, ao se deparar com diferentes versões de uma mesma história sobre Garrincha, conclui que apenas uma das versões é verdadeira. Em texto que tem o sugestivo título de A mentira tem pernas tortas, publicado na revista Placar às vésperas do lançamento da biografia que produzira, Castro descreve assim a missão que se impõe de descobrir "a verdade" sobre Garrincha:

Um dos thrills de se escrever uma biografia é a quantidade de lendas que vão sendo derrubadas à passagem do biógrafo. O herói continua herói - talvez até maior que a lenda -, só que diferente. Muito do que já se escreveu sobre o personagem transforma-se em mingau à medida que o biógrafo apenas cumpre sua obrigação de duvidar das histórias tidas como certas e sai em busca da verdade (CASTRO, 1995, p. 96).

Se, por um lado, Castro sente-se obrigado a partir em busca de uma verdade única, o presente trabalho, por outro, concorda com pressupostos antropológicos que veem as contradições existentes entre diferentes versões de uma mesma história como significativas. Assim, a construção do objeto deste artigo segue um rumo diferente do tomado por Castro no tratamento das histórias sobre Garrincha, posto que as diferenças existentes entre as versões de uma mesma história são aqui assumidas como dados não descartáveis, de forma semelhante ao que propõem Leach (1970) em suas análises da mitologia Kachin e Goody (2010) em seu estudo sobre o mito Bagre dos LoDagaa.

Em Political Systems of Highland Burma (1970), Leach pesquisa a mitologia Kachin buscando realizar um afastamento teórico-metodológico em relação aos pesquisadores que antes dele se debruçaram sobre os mitos produzidos por povos daquela região. Para Leach, os que até então haviam analisado os mitos dos Kachins partiam de pressupostos funcionalistas que propunham que todos os aspectos de uma cultura deveriam encontrar-se integrados na formação de um todo coerente. Ávidos por fazerem convergir os dados com esse esquema funcionalista, os etnógrafos que se deparavam com diferentes versões de um mesmo mito sentiam-se impelidos a descartar as suas supostas inconsistências e selecionar a versão que lhes parecia ser a mais correta.

$\mathrm{O}$ afastamento de Leach em relação a essa perspectiva se dá em dois sentidos. Em primeiro lugar, o autor nega a necessidade de integrar os mitos em um conjunto consistente "Now in my view it is unnecessary to postulate this kind of consistency" (LEACH, 1970, p. 265). Em segundo lugar, afirma que quando o antropólogo se depara com versões diferentes de uma mesma história, nenhuma delas pode ser definida como mais verdadeira, já que esta 
postura levaria ao descarte das variações existentes e, consequentemente, à formulação de pressupostos reducionistas sobre a sociedade que tomariam como simples e rígida: "If mythological inconsistencies are eliminated on the grounds that there could after all be only one set of historical facts, inconsistencies in traditional law and custom are also necessarily eliminated and the whole scheme becomes rigid and simple" (LEACH, 1970, p. 268). Concluindo seu raciocínio, Leach sugere:

In the case of Kachin mythology there can be no possibility of eliminating the contradictions and inconsistencies. They are fundamental. Where there are rival versions of the same story, no one version is 'more correct' than any other. On the contrary, I hold that the contradictions are more significant than the uniformities (LEACH, 1970, p. 265).

Por sua vez, ao analisar os mitos LoDagaa em Myth, Ritual and the Oral (2010), Jack Goody reconhece as diferenças entre recitações surgem como especialmente significativas para a produção de dados. Valendo-se do emprego de um gravador portátil, o antropólogo vislumbrou a possibilidade de documentar as recitações enquanto estas ocorriam. Antes, servido apenas de papel e caneta diante de longas recitações, Goody se via na necessidade de recorrer a intermediários que pudessem, após o fim da cerimônia, auxiliá-lo na transcrição do mito recitado. Com o gravador em mãos, porém, tornava-se possível documentar a recitação ainda no contexto de realização da cerimônia, o que, consequentemente, lhe permitia desenvolver uma análise posterior do papel da audiência na performance. Outro ponto destacado por Goody é o de que a gravação de diversas versões de uma mesma história possibilita a posterior comparação das semelhanças e das diferenças entre elas. Limitando-se ao estudo do mito Bagre, Goody afirma da seguinte maneira as vantagens trazidas pelo emprego do gravador portátil:

But from my point of view what was most important was that, as distinct from working with pencil and paper in a field situation, one could now record with relative ease a plurality of versions of a single recitation. That was important because, in the case of the Bagre, these showed considerable variation, whereas if I believed the actors themselves, every version was the same (GOODY, 2010, p. 58).

Segundo Goody, antes do acesso a diversas versões de uma mesma recitação, ele teria sido convencido por seus interlocutores de que a versão do mito Bagre que conhecia era invariável: "When I first recorded the Bagre I was convinced (because the LoDagaa told me) that the recitations were 'one' (boyen), the same. So they were for LoDagaa” (GOODY, 2010, p. 03). Porém, a partir do momento em que o gravador lhe possibilitou o acesso a uma 
pluralidade de versões, ele constatou que estas poderiam ser recitadas por uma mesma pessoa em diferentes situações ou por pessoas diferentes em uma mesma situação, o que levou a novas conclusões em seus estudos. Daí a problematização de análises que tomam uma determinada versão de um mito como a única possível - como um ponto de referência associando-a com a estrutura social, o que acaba por sugerir a existência de relações fixas entre o mito e a sociedade. De acordo com Goody:

The introduction of the audio recorder in work in the social sciences reveals a flexible relation between myth and society. This looseness must be acknowledged in contrast to the supposition of many earlier anthropologists. The recitation of a myth is not simply an exercise in exact reproduction, as if one was copying a passage of Milton's Paradise Lost. On the contrary, it involves the incremental creation of a large number of variants, which results not simply in changes in the surface structure but also in the deep structure of myth (GOODY, 2010, p. 63).

Concordando com Goody que as variações existentes entre versões de um mesmo mito não podem ser descartadas a priori - "my argument is that one can never know where these variations might lead until one records and examines" (GOODY, 2010, p. 03) - e seguindo a proposta de Leach de que nenhuma versão de uma história deve ser tomada como mais correta que outra, pretende-se neste artigo por em evidência o processo de construção de diferentes versões de uma mesma história sobre Garrincha, versões estas que, a despeito das divergências, são contadas por seus narradores como verdadeiras.

Diante da vasta produção de conteúdos simbólicos sobre Garrincha, e indo ao encontro da afirmação de Freitas de que "adentrar os meandros todos que levam à construção de uma imagem como a de Garrincha na memória coletiva do brasileiro é sem dúvida algo irrealizável" (FREITAS, 2014, p. 87), acredita-se ser pertinente definir um lócus de pesquisa que seja o mais delimitado possível. Neste sentido, o presente trabalho concentrará sua análise em algumas versões de uma única história sobre Garrincha, que será chamada daqui em diante de a "história do rádio".

A estrutura da "história do rádio" pode ser assim descrita: um jogador de futebol representado como ingênuo e limitado intelectualmente excursiona com sua equipe a um país europeu. Esse jogador adquire um rádio e, mais tarde, ao testá-lo, verifica que todas as estações disponíveis falam apenas uma língua que ele não entende, no caso, a língua local das transmissões radiofônicas passíveis de serem sintonizadas pelo aparelho. Percebendo uma possibilidade de levar vantagem na situação, um segundo personagem, representado como malandro, convence o jogador de que o rádio seguiria transmitindo apenas naquela língua, mesmo no Brasil. Decepcionado por não conseguir ouvir nenhuma música ou programação 
em português, o jogador representado como ingênuo conclui que o aparelho não lhe será útil, no que aquele representado como malandro se oferece para comprar o equipamento por um valor menor do que o pago inicialmente pelo produto.

Por um lado, a escolha de investir em versões da "história do rádio" como lócus de pesquisa se justifica por sua notável difusão, que de tão ampla permite a Castro a afirmação hiperbólica de que "não há brasileiro que não conheça a história" (CASTRO, 1995, p. 96). Por outro, pensar as versões da "história do rádio" coloca-se como frutífero para os objetivos deste trabalho devido à gama de variações existentes, que modificam o país onde teria ocorrido o caso, o personagem que figurou na história junto com Garrincha, as características do rádio e até mesmo o papel ocupado por Garrincha na trama. Essa última variação traz consigo um outro atrativo, posto que analisar versões da "história do rádio" nas quais Garrincha aparece representado ora como malandro, ora como ingênuo, permite a apresentação de alguns argumentos acerca da construção das duas representações dominantes sobre o jogador.

\section{II}

Realizando a ressalva de que existem versões da "história do rádio" que não são protagonizadas por Garrincha ${ }^{3}$, os próximos parágrafos dedicar-se-ão a apresentar algumas dentre as muitas versões já narradas. A versão contada por Mário Trigo, dentista da seleção brasileira na Copa do Mundo de 1958, no livro Eterno Futebol (2002), é uma das que representam Garrincha como ingênuo, assim como as narradas por Mário Américo, massagista da seleção brasileira entre as décadas de 1940 e 1970, no livro Memórias de Mário

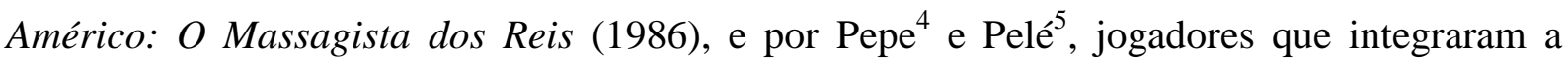
seleção brasileira junto com Garrincha em 1958.

Na versão de Mário Trigo, o caso teria ocorrido na Suécia, quando a seleção brasileira participava da Copa do Mundo de 1958. Em um dia de folga da delegação, Garrincha perguntou ao próprio Trigo se este poderia acompanhá-lo até uma loja para orientá-lo na compra de alguns discos. Chegando à loja, porém, o que interessou a Garrincha foi um pequeno rádio transistorizado, o qual acabou por comprar. Um tempo depois, na sala de massagens do hotel, Garrincha ouvia o rádio enquanto era atendido pelo massagista Mário Américo. Espertamente, este alerta a Garrincha que o rádio só falava sueco e que o mesmo ocorreria no Brasil, convencendo o jogador a vender-lhe o aparelho, que havia sido comprado pelo preço de 180 coroas, por 90 coroas. Ao saber da venda pelo próprio Garrincha, Mário 
Trigo teria comprado um novo e igual rádio, que entregou ao jogador com os dizeres: "Mané, este fala todas as línguas" (TRIGO, 2002, p. 156). Ao ser indagado por Garrincha o motivo de não ter sido aconselhado a comprar este aparelho na primeira oportunidade, Trigo termina o relato constatando que "não adiantava explicar mais nada" (TRIGO, 2002, p. 156).

As versões contadas por Pepe e Mário Américo, ambos companheiros de Garrincha na delegação brasileira no Mundial de 1958, assemelham-se com a versão de Mário Trigo em dois pontos: nestas versões a história teria acontecido na Suécia e o próprio Mário Américo foi quem comprou o rádio de Garrincha. Contudo, entre si, essas três versões também são repletas de diferenças, como em relação aos valores que Garrincha pagou pelo aparelho e que Mário Américo teria lhe pagado posteriormente. Como visto, Trigo relata que Garrincha teria comprado o rádio por 180 coroas e vendido a Mário Américo pela metade do preço. Para Pepe, porém, Garrincha adquiriu o aparelho por 40 dólares e o vendeu a Mário Américo por 10 dólares, enquanto o próprio Mário Américo conta que pagou 40 dólares pelo rádio que Garrincha comprara por mais de 100 dólares.

As diferenças entre essas versões não param por aí. Se Trigo relata que Garrincha comprou "um rádio pequeno, muito interessante" (TRIGO, 2002, p. 155), Pepe, por outro lado, conta que Garricha adquirira um rádio “enorme”. O momento da negociação entre Garrincha e Mário Américo também coloca-se como um ponto de divergência. Tomando a realização da Copa do Mundo como ponto de referência temporal, o próprio Mário Américo diz que comprou o rádio de Garrincha "logo no começo da concentração" (MATTERUCCI, 1986, p. 118), enquanto Pepe afirma que o ocorrido se deu "um pouco antes de vir embora, no dia anterior, já campeões da Copa".

Mais variações surgem com a inclusão da versão narrada por Pelé. Como as três versões anteriores, a de Pelé também relata que o ocorrido se deu na Suécia, porém diverge das mesmas ao afirmar que Garrincha não comprou o rádio na loja. De acordo com Pelé, Garrincha teria se irritado ainda na loja por não entender a língua veiculada nas transmissões radiofônicas, razão pela qual se negou a comprar o aparelho enquanto reclamava em voz alta: "Não vou levar essa porcaria não. Não entendo nada que ele fala". Tem-se, ainda, que a versão de Pelé concorda com a de Pepe quanto ao tamanho (grande) do aparelho, mas há discordância em relação às marcas. Para Pelé, os rádios eram das marcas Grünfeld e Phillips, enquanto para Pepe, da marca Telefunken.

Como salientado, da mesma forma que há versões da "história do rádio" que caracterizam Garrincha como ingênuo, há também versões que o representam como malandro, como as contadas pelos jornalistas Sandro Moreyra, em Histórias de Futebol (1998), e Ruy 
Castro, em Estrela Solitária: Um brasileiro chamado Garrincha (1996), e pelo jogador Nilton Santos, que atuou com Garrincha durante mais de uma década, em Minha bola, Minha vida (1998). Um ponto semelhante entre as três versões, além, claro, de representarem Garrincha como malandro, é que todas relatam que Garrincha estava em excursão com o Botafogo, e não com a seleção brasileira. Entretanto, enquanto Moreyra conta que o clube excursionava a Frankfurt (Alemanha), Nilton Santos e Castro afirmam que o ocorrido se deu na cidade de Copenhague (Dinamarca). Mais divergências entre as versões surgem na comparação de quem é representado como ingênuo e no destino final do rádio.

$\mathrm{Na}$ versão de Moreyra, o rádio teria sido adquirido pelo goleiro Manga no aeroporto de Madri pelo valor de 180 dólares. Quando chegou ao hotel, em Frankfurt, Manga tentava de todas as maneiras sintonizar estações de rádio brasileiras, ao que Garrincha teria dito, “malandramente” (MOREYRA, 1998, p. 57), que isso só seria possível se o rádio tivesse um botão em sua lateral. Como o rádio não o tinha, Garrincha se propôs a pagar 20 dólares pelo aparelho, proposta que foi aceita por Manga, que, feliz, saiu a contar para os companheiros: "Finalmente enganei aquele torto. Vendi para ele um rádio com defeito, que só fala língua de gringo" (MOREYRA, 1998, p. 57).

No relato de Castro, o representado como ingênuo é Hélio, jogador do botafoguense de uma "tocante ingenuidade" (CASTRO, 1996, p. 91). Hélio, ao ligar o rádio recémcomprado, sintonizou apenas estações dinamarquesas, ao que Garrincha teria dito: "Se você não trocar as válvulas quando chegar ao Brasil, ninguém vai entender o que o locutor está falando. E lá não tem para vender dessas válvulas”. (CASTRO, 1996, p. 91). A partir deste ponto, Castro deixa o final da história em aberto, afirmando não saber se Hélio devolveu o rádio para a loja ou comprou novas válvulas, mas afirma que Garrincha não se beneficiou do que teria sido apenas uma "brincadeira típica" (CASTRO, 1996, p. 91). Ainda sobre o destino do rádio, a versão de Nilton Santos, que também representa Hélio como ingênuo, difere da de Castro, ao narrar que, após o diálogo com Garrincha, Hélio "tratou de vender o rádio mais barato e o mais rápido o possível” (SANTOS, 1998, p. 111).

Após ter apresentado as versões da "história do rádio" que formam o lócus deste trabalho, deve-se destacar que todas são relatadas, umas mais explicitamente do que outras, como verdadeiras. As versões contadas por Pelé, Pepe, Nilton Santos, Mário Trigo e Mário Américo fundamentam seu caráter de "verdade" no argumento testemunhal do "estar lá", sendo todas elas narradas na primeira pessoa do plural. Segundo Trigo, após um pedido de Garrincha, eles teriam ido juntos comprar o rádio: "Eu o levei na mais moderna casa de discos de Gotemburgo" (TRIGO, 2002, p. 156). Mário Américo, por sua vez, conta uma versão na 
qual ele mesmo teria comprado o rádio de Garrincha. Já Nilton Santos começa assim seu relato: "Noutra época, o Botafogo estava excursionando e acabamos por chegar a Copenhague" (SANTOS, 1998, p. 111). Pelé e Pepe não apenas narram suas versões na primeira pessoa do plural, mas reforçam a veracidade da história com intervenções pontuais. Pepe, na palestra em que narra sua versão, afirma: "É verdade isso". Por fim, Pelé, enquanto expõe sua versão em entrevista, constantemente interrompe sua narrativa com afirmações como: "Não é piada", "Me lembro até hoje", "Isso não foi mentira, eu estava junto".

Castro, antes de iniciar o seu relato, chama a atenção para a existência de desencontros em diversas versões da "história do rádio" e, após afirmar que "o fato, porém, é outro" (CASTRO, 1996, p. 91), desconsidera a validade das versões que não convergem com a que ele próprio narra. Tamanho é o convencimento quanto à veracidade de sua versão que o jornalista sequer entende como uma "brincadeira típica de Garrincha foi distorcida de forma a colocá-lo como o otário da história" (CASTRO, 1996, p. 91), negando, assim, as versões que representam Garrincha como ingênuo. Diferente dos narradores que foram companheiros de Garrincha e que contam suas versões na primeira pessoa do plural, Castro não constrói a verossimilhança de sua versão com base em argumentos do tipo "eu estive lá". Ao invés disso, sustenta sua versão como verdadeira valendo-se das 500 entrevistas que realizou ao longo da produção da biografia de Garrincha.

Dentre os narradores da "história do rádio" aqui selecionados, Sandro Moreyra é o único que não afirma explicitamente sua versão como verdadeira. Embora trate-se de um jornalista que trabalhou com futebol por mais de 30 anos, realizou diversas viagens para cobrir o Botafogo e a seleção brasileira e, não menos importante, de Garrincha "era grande amigo" (CASTRO, 1995, p. 96), Moreyra nem confirma se esteve presente na excursão que deu origem a sua versão da "história do rádio", nem, no caso de uma suposta ausência, diz quem teria lhe relatado o ocorrido.

\section{III}

Um dos argumentos que o exposto até aqui permite sustentar é o de que nenhuma das versões da "história do rádio" alcançou o status de "versão referência", no sentido de se colocar como aquela a ser consultada para se retirar dúvidas ou obter informações sobre o que teria ocorrido "de verdade". Nem mesmo a versão de Castro, baseada em pressupostos pretensamente objetivos, tornou-se referência, visto que a maioria das outras versões da 
"história do rádio" apresentadas foi narrada após a publicação da versão do jornalista e, mesmo assim, apresentam divergências entre si.

Sugerindo que a ausência de uma "versão referência" encontra-se no cerne da variedade de versões da "história do rádio", acredita-se que um ponto de partida rumo ao entendimento da construção destas diferentes versões pode ser encontrado nas ideias elaboradas por Goody sobre a literatura oral, que seria assim definida pelo próprio: "Oral 'literature' was the standard form (or genre) found in societies without writing. The term is also used to describe the quite different tradition in written civilizations where certain genres are transmitted by word of mouth or are confined to the unlettered (the "folk)" (GOODY, 2010, p. 41). Particularmente, o encontro aqui desejado é com as ideias de Goody acerca das modificações na transmissão cultural oral então proporcionadas pelo advento da escrita.

Pensando sociedades não-letradas, Goody, em parceria com Watt, sugere que os elementos culturais mais significativos encontram-se estocados na memória dos indivíduos, sendo transmitidos através de contatos face a face por intermédio de símbolos verbais: "As we have remarked, the whole content of the social tradition, apart from the material inheritances, is held in memory" (GOODY; WATT, 1963, p. 307). Tem-se, assim, que em sociedades sem escrita o conteúdo transmitido em recitações ancora-se na memória individual, que, imperfeita, produz esquecimentos, abrindo espaços que são preenchidos pela criatividade do recitador da história: "there is forgetting as well as creation; indeed, in oral cultures they are two sides of the same coin. Forgetting requires invention, creation; creation probably requires some forgetting" (GOODY, 2010, p. 66).

Essa relação entre esquecimento e criação possibilitada pela imperfeição da memória encontra-se na base dos argumentos de Goody para a existência, nas sociedades orais, de diversas versões de uma mesma história, que podem apresentar entre si variações significativas: "People invent and fill in where they do not have perfect recall. One result is a plurality of versions spread over time (and space) [...]" (GOODY, 2010, p. 53). O autor, contudo, não limita seus estudos às transmissões culturais em sociedades sem escrita. Pelo contrário, um de seus maiores interesses consiste em compreender como a transmissão cultural oral foi influenciada pela escrita.

Com a ressalva de que Goody não pensa a escrita como substituta da oralidade, mas sim como uma adição cujo advento traz profundas influências sobre os discursos orais, um dos focos de análise do autor reside nas mudanças proporcionadas na memorização de histórias com a adição da escrita. Segundo Goody, a escrita, pela capacidade de fixar o texto, possibilita o desenvolvimento de técnicas mnemônicas que seriam imprensáveis em 
sociedades puramente orais. Uma dessas técnicas, por exemplo, seria a de decorar, através de leituras e releituras de uma versão fixa, o texto a ser recitado: "The practice of learning things 'by heart' seems to be a feature of written cultures, where sentences can be read over and over again, without variations [...]" (GOODY, 2010, p. 153). Outra técnica dependente da escrita acionada na busca por reduzir os espaços deixados pela memória seria a de rimar: “[...] one of the main mnemonic techniques, the system of rhyme, seems largely to depend on writing, or the visual interiorization of the word" (GOODY, 2010, p. 65).

Dentre as ideias elaboradas por Goody sobre as mudanças nos discursos orais oriundas da adição da escrita aquelas que mais interessam a este trabalho são as que pensam a produção de uma versão fixa que adquire o status de referência na busca por correções e confirmações da história a ser recitada: "Only with writing and with oral recitations in literate societies [...] is it possible to refer the oral transmission to an original, partly because writing introduces a new dimension to verbal memory and partly because reference can then always be made back to the "correct' version" (GOODY, 2010, p. 46). Destarte, se nas recitações de histórias em sociedades desprovidas das técnicas mnemônicas que acompanham a adição da escrita o processo de criação é o responsável por ocupar os espaços deixados pelas falhas na memória - In purely oral cultures, re-creation usually takes the place of a concern with exact recall (GOODY, 2010, p. 46) -, por outro lado, a criação de uma "versão referência" fixada pela escrita tende a limitar a criação do recitador e, consequentemente, a variação de versões de uma mesma história. Neste sentido, sobre os épicos recitados em sociedades letradas, Goody afirma: "Hence, as we have seen, one would expect much less variation there than in the case of a purely oral culture where there were no such mnemonics, no such constraints, no fixed text lying in the background" (GOODY, 2010, p. 77).

Conforme mencionado, os argumentos desenvolvidos por Goody acerca da literatura oral servirão aqui como um ponto de partida para se compreender a variedade de versões existentes da "história do rádio". Contudo, antes de levar mais a fundo essa sugestão, parece pertinente realizar uma ressalva. Preocupado em analisar as consequências do letramento, Goody concentra sua análise em dois polos: de um lado, as versões de histórias recitadas em sociedades puramente orais, e, de outro, as versões contadas em sociedades letradas por recitadores que podem recorrer a um registro fixo tido como correto. Dito de outra forma, devido aos seus objetivos específicos, Goody não elabora argumentos sobre os casos em que uma determinada história apresenta mais de uma versão escrita sem que nenhuma delas adquira o status de referência de correção. Contudo, isso não constitui um empecilho ao estabelecimento de diálogos com as ideias de Goody, objetivando-se pensar casos, não raro 
ocorridos em sociedades letradas, nos quais a ausência de uma versão com o status de referência leva à coexistência de versões que, mesmo congeladas pela escrita, apresentam variações significativas. Como proposto, esse seria justamente o caso da "história do rádio".

Olhando a "história do rádio" a partir de uma perspectiva que dialoga com as ideias de Goody, uma primeira observação que se pode fazer é a de que, na ausência de uma "versão referência" da "história do rádio", seus narradores possuem maior liberdade para ocupar os espaços deixados pelo esquecimento com sua criatividade. Entretanto, como aponta Goody, a análise de versões incongruentes não deve limitar-se ao recitador, devendo estender-se também ao contexto de transmissão e à audiência: "With any literature, it is important to consider not only the speaker but the audience and the situational context" (GOODY, 2010, p. 47). Com o intuito de ilustrar essa necessidade, o autor recorre ao épico Fulani de Silâmaka and Poullôri, recitado por menestréis africanos influenciados pela tradição islâmica escrita.

Sobre esse épico, Goody ressalta que apesar de fixo em certas características, o texto varia consideravelmente, seja com relação a que episódio receberia maior destaque ou qual herói seria mais exaltado. Essas variações decorrem em parte da ação dos menestréis, como é possível interpretar da afirmação de Goody realizada em diálogo com Seydou: "Seydou describes how the legend crossed frontiers, was spread by the mouths of griots who, 'each in his own fashion and according to his own practice, have enriched, transformed, rebuilt from diverse elements borrowed from other recitals"" (GOODY, 2010, p. 126). Entretanto, segue o autor, assim como são resultado da criatividade do recitador, as variações nas versões do épico também relacionam-se diretamente com a audiência que acompanha a recitação e com a situação de transmissão. Nos termos de Goody:

Each time the griots are playing to a specific but varying audience. They live by the responses of that audience; they travel, play the lute, and change their story to fit the community in which they are working. In other words, while the Fulani epic, like the epic in general, seems to occur in a society influenced by writing, the form it takes varies considerably depending upon the bard, the time, the situation (GOODY, 2010, p. 126).

Se a perspectiva que se pretende adotar para entender a variedade de versões da "história do rádio" é a de analisar a criação do narrador como parte de um processo contextual, crê-se que as ideias elaboradas por Leach acerca da mitologia Kachin têm muito a contribuir. Com o objetivo de pensar a organização social Kachin pelo ângulo das narrativas mitológicas, Leach questiona como a mitologia relaciona-se com as mudanças na estrutura social: "How can mythology be held to justify change, in the social structure?" (LEACH, 
1970, p. 264). Vendo mito e ritual como formas semelhantes de discurso - "[...] myth and ritual are essentially one and the same. Both are modes of making statements about structural relationships" (LEACH, 1970, p. 264) -, o autor propõe que a relação entre as narrativas mitológicas e a estrutura social é de tal ordem que as instabilidades estruturais acabam por ser também representadas no sistema ritual. Segundo Leach: "[...] the social structure is 'represented' in ritual. But if the social structures with which we are here dealing are unstable, this instability must also be 'represented' in the ritual system" (LEACH, 1970, p. 264).

O raciocínio de Leach sobre a fluidez das narrativas mitológicas segue com a argumentação de que a recitação de um mito tem como um dos propósitos a validação do status social de quem conta a história ou do contratante de quem a recita, haja vista que entre os Kachins a narração de histórias tradicionais é também uma ocupação profissional. Tem-se, então, que entre os Kachins os interesses do recitador surgem como uma das variáveis que leva à existência de diferentes versões de uma mesma história: "One might then infer almost from first principles that every traditional tale will occur in several different versions, each tending to uphold the claims of a different vested interest" (LEACH, 1970, p. 266). É neste sentido de afirmar a variedade de versões de uma mesma história como resultado dos interesses de quem a conta que Leach destaca a inexistência de uma "versão autêntica" dos mitos contados pelos Kachins com a qual todos concordariam. Para o autor:

There is no 'authentic version' of Kachin tradition to which all Kachins would agree, there are merely a number of stories which concern more or less the same set of mythological characters and which make use of the same kinds of structural symbolism [...], but which differ from one another in crucial details according to who is telling the tale (LEACH, 1970, p.2 66).

Ilustrando a afirmação supracitada, Leach apresenta as diferenças existentes nas versões do mito Kachin sobre a origem de Nsu nat, o espírito do ciúme, a partir do relato de dois etnógrafos, Gilhodes e Hanson, que publicaram versões sobre esse mito que podem ser interpretadas como invertidas. Na versão de Gilhodes, o mais velho dentre os irmãos tem ciúme do mais novo, que é favorecido pelo espírito Nsu nat. No fim, o irmão mais velho morre afogado em um caixão que ele preparou para o irmão mais novo, que sobrevive e se torna um chefe rico. $\mathrm{Na}$ versão de Hanson, o inverso ocorre, de modo que é o irmão mais novo quem morre afogado no caixão que preparara. Afirmando que nenhuma das duas versões deve ser tomada como mais correta do que a outra - "Neither of these versions can be said to be more correct than the other" (LEACH, 1970, p. 266) - Leach argumenta que as variações ocorrem porque em contextos de conflito entre irmãos, tanto o mais velho quanto o 
mais novo pode realizar oferendas a Nsu nat, o espírito do ciúme. Se o irmão mais novo fizer a oferenda, a versão de Gilhodes será acionada. Caso contrário, isto é, se quem faz a oferenda é o irmão mais velho, a versão narrada é a de Hanson. Assim, conclui Leach: “The bard-priest (dumsa) will adapt his stories to suit the audience which hires him" (LEACH, 1970, p. 266).

Antes de prosseguir, acredita-se ser necessário ressaltar que, apesar de possíveis aproximações entre suas obras, Goody e Leach possuem objetivos notadamente diferentes. Grosso modo, o primeiro deseja verificar a influência da escrita na transmissão cultural oral, enquanto o segundo quer compreender de que forma as narrativas mitológicas justificam as mudanças sociais. Assim, embora afirmem que diante da coexistência de diferentes versões de uma mesma história nenhuma deve ser tomada como mais verdadeira do que outra, Goody e Leach sustentam estas afirmações em argumentos diferentes. Para Goody, a diversidade de versões de um mesmo mito é possível devido a propriedades intrínsecas à transmissão cultural oral, no sentido de que o conteúdo transmitido baseia-se na memória individual, que, ao falhar, abre espaços que são preenchidos pela criatividade do recitador: "There is forgetting, and there is creation, if only to fill the gaps" (GOODY, 2010, p. 66). Já nos argumentos de Leach, a diversidade de versões de um mesmo mito ocorre pois as enunciações se dão em um contexto de disputa de poder, de modo que cada versão tende a ser contada de modo a sustentar certos interesses particulares: "Since any social system, however stable and balanced it may be, contains opposing factions, there are bound to be different myths to validate the particular rights of different groups of people" (LEACH, 1970, p. 277).

Tendo realizado essas ressalvas acerca das diferenças entre os objetivos de Goody e Leach em seus estudos, foca-se novamente nas aproximações destacando que ambos propõem que um caminho para se pensar a existência de diversas versões de uma mesma história passa pela adoção de uma perspectiva contextual-relacional. Neste sentido, o passo final deste trabalho consiste em analisar a construção de diferentes versões da "história do rádio" a partir de uma óptica que tome cada versão como um produto da relação entre os interesses dos narradores e o contexto.

De forma um pouco mais delimitada, crê-se que uma das formas mais profícuas de se analisar uma versão da "história do rádio" consiste em pensar sua relação com as outras narrativas que fazem parte do mesmo conjunto em que ela se inclui, seja este conjunto um livro, uma entrevista ou uma palestra. Essa perspectiva contextual, que toma cada versão da "história do rádio" como parte integrante de um conjunto, possibilita o acesso a um maior número de representações sobre Garrincha produzidas pelo mesmo narrador, permitindo, assim, a realização de interpretações acerca de seus interesses em representar Garrincha como 
ingênuo ou malandro. Nessa linha, os próximos parágrafos dedicam-se a analisar contextualmente duas versões da "história do rádio". Na primeira, narrada por Mário Américo, Garrincha é representado como ingênuo, enquanto o próprio Mário Américo figura como malandro. Na segunda, narrada por Moreyra, Garrincha é representado como malandro e Manga, como ingênuo. A escolha dessas duas versões se justifica por elas se situarem em obras que contém outras narrativas não apenas sobre Garrincha, mas também sobre os outros protagonistas em questão, ou seja, Mário Américo e Manga, respectivamente.

A versão narrada por Mário Américo da "história do rádio" encontra-se na seção intitulada "Os Homens” do livro Memórias de Mário Américo: O Massagista dos Reis (1986). Nessa seção, Mário Américo narra histórias sobre os jogadores com os quais conviveu durante as mais de três décadas em que foi massagista da seleção brasileira. Na parte dedicada a Garrincha, é possível encontrar com frequência representações sobre este jogador como ingênuo, como a seguinte declaração, que abre a seção: "Seu Mané... Manuel Garrincha... o nome mais apropriado seria Cândido ou Angélico, pois nunca existiu criatura mais inocente, de intenções mais puras. Um eterno menino de 12 anos" (MATTEUCCI, 1986, p. 114). Novas representações de Garrincha como ingênuo surgem quando Mário Américo narra as histórias envolvendo o jogador com a cantora Elza Soares, com quem foi casado. Nesses relatos, Garrincha surge como "inocente, um sujeito boníssimo, pacato e vítima da própria glória" (MATTEUCCI, 1986, p. 117).

Ampliando o escopo de observação, é possível analisar a "história do rádio" considerando-se mais detalhadamente o papel de malandro ocupado por Mário Américo do que o papel de ingênuo imputado a Garrincha. Muito provavelmente a história mais conhecida protagonizada por Mário Américo é a que conta como o massagista conseguiu invadir o campo após o término da final da Copa do Mundo de 1958, na qual a seleção brasileira foi campeã, e, enganando o juiz da partida e os policiais, levar a bola do jogo para o vestiário, escondê-la e trazê-la para o Brasil. Não por coincidência essa é a história que abre o livro de memórias de Mário Américo. E não por coincidência, também o massagista produz nessa narrativa uma autorrepresentação de si como malandro, assim como faz em sua versão da "história do rádio", vide o seguinte comentário sobre o feito de ter conseguido ficar com a bola: "Acredito que havia mais de vinte pessoas de olho naquela bola, mas felizmente nem todos eram latinos como eu. [...] Eu sei que todo crioulo é descendente de africanos, mas crioulo brasileiro é latino na malícia” (MATTEUCCI, 1986, p. 11).

A versão da "história do rádio" de Sandro Moreyra, por sua vez, encontra-se no livro Histórias de Futebol (1998), na parte intitulada "Manga, Garrincha e outros amigos", cujo 
título por si só revela que a seção contém outras narrativas tanto sobre Garrincha quanto sobre Manga. Pensando a versão da "história do rádio" narrada por Moreyra em comparação com outras narrativas sobre Garrincha presentes na obra em questão, é possível interpretar a existência de uma convergência de representações nas quais Garrincha é frequentemente caracterizado como malandro. Por exemplo, além de narrar histórias em que Garrincha escapa da concentração para ir a festas durante as excursões do Botafogo, Moreyra conta que Garrincha gostava de uma brincadeira na qual enganava um companheiro de equipe, "de preferência Manga" (MOREYRA, 1998, p. 58), comunicando-lhe que alguém chamado Leão havia telefonado, pedindo que retornasse a ligação para um determinado número. Garrincha, então, entregava ao companheiro um número de telefone que este vinha a saber, posteriormente, ser o do Jardim Zoológico.

Caso sejam incluídas no conjunto de narrativas as histórias contadas por Moreyra sobre Manga, novamente se encontra uma convergência de representações. Neste caso, assim como na versão do jornalista da "história do rádio", Manga é também representado como ingênuo e intelectualmente limitado em outras narrativas presentes no livro, como pode-se interpretar pelas seguintes sínteses das histórias relatadas por Moreyra. Manga, confundindo o título "As Pirâmides do Egito" com “As Piranhas do Egito" (MOREYRA, 1998, p. 57) teria ido ao cinema para assistir um filme bíblico pensando se tratar de um filme pornográfico. Manga teria respondido a um gago que lhe perguntara onde se localizava a escola de gagos dizendo: "Meu amigo, você não precisa de escola, já gagueja muito bem" (MOREYRA, 1998, p.63). Por fim, desejando afirmar que, caso fosse suspenso de um jogo, o advogado do Botafogo entraria na Justiça com um pedido de habeas corpus, Manga teria dito o seguinte: "Não há perigo. O homem disse que se me suspenderem ele entra com um pedido de Corpus Christi para mim" (MOREYRA, 1998, p. 74).

Como se vê, da mesma forma que a análise contextual das histórias narradas por Mário Américo permite associar a sua versão da "história do rádio" aos seus interesses em se autorrepresentar como malandro (e, consequentemente, representar Garrincha como ingênuo), a versão da "história do rádio" relatada por Sandro Moreyra está claramente relacionada com seus interesses em representar, simultaneamente, Garrincha como malandro e Manga como ingênuo. 
O acervo de conteúdos simbólicos produzidos sobre Garrincha talvez seja o mais amplo em se tratando de um futebolista brasileiro. Dentre os materiais presentes nesse acervo, destacam-se histórias narradas com o intuito de contar passagens da vida do jogador, dentro ou fora dos gramados. Não raro, essas histórias apresentam versões que contam com diferenças não apenas periféricas, mas que dizem respeito à própria forma de representar Garrincha, como é o caso da "história do rádio", na qual Garrincha tanto pode ser representado como malandro quanto como ingênuo. Através de uma breve análise de algumas versões da "história do rádio", o presente artigo buscou por em evidência propriedades do processo de construção narrativo que ensejam variações em torno de uma mesma história, mostrando que, a despeito de possíveis divergências entre si, todas possam ser igualmente narradas como verdadeiras.

Neste sentido, o argumento conclusivo a ser apresentado diz respeito ao fato de que, se a escrita (assim como a gravação de imagens) é capaz de fixar o texto, nem todo texto tornase obrigatoriamente uma "versão referência" a ser consultada na busca por correções ou confirmações. Prova disso é que das sete versões da "história do rádio" apresentadas, cinco encontram-se registradas pela escrita e duas por gravação de imagens. No entanto, nenhuma delas, nem as que se baseiam em argumentos do tipo "eu estava lá", nem as que se ancoram em pressupostos objetivistas de busca pelo fato jornalístico, alcançou o status de "versão referência".

$\mathrm{Na}$ ausência de uma "versão referência" da "história do rádio", seus narradores acabam por ter maior liberdade criativa na construção de suas versões. Por sua vez, tal processo criativo não se limita à capacidade inventiva do narrador, sendo produto também do contexto no qual a narrativa se situa. É precisamente por essa razão que cada versão da "história do rádio" deve ser lida em relação com as outras histórias que se lhe acompanham. Só assim torna-se possível entender como um mesmo personagem (como, no caso, o Garrincha) pode ser representado tanto como malandro, quanto como ingênuo, sem que isso necessariamente implique uma contradição ou signifique a superioridade de uma versão sobre $\mathrm{a}(\mathrm{s}) \operatorname{outra}(\mathrm{s})$.

\section{NOTAS}

1) Manoel Francisco dos Santos era o nome do futebolista que se tornou popularmente conhecido como Garrincha.

2) Assim como fazem Soares e Bartholo, vale recordar que "Ruy Castro é jornalista e a idéia de verdade e objetividade da notícia é um valor nesse campo profissional" (SOARES; BARTHOLO, 2009, p.178).

3) Aliás, as versões da "história do rádio" não se limitam necessariamente sequer a narradores e protagonistas brasileiros. No programa Raza Deportiva, da estação de rádio norte-americana ESPN Deportes, que foi ao ar no dia 12 de junho de 2015, o jornalista uruguaio Leo Vega relatou uma versão envolvendo os jogadores José 
"Jamaicón" Villegas, representado como ingênuo, e Guillermo "El Tigre" Sepúlveda, representado como malandro. Programa disponível em: http://espndeportes.espn.go.com/espndeportesradio/play?id=2396910. Acessado em 13/06/2015.

4) O vídeo com a versão da "história do rádio" que Pepe narra em uma palestra está disponível em: http://esportes.terra.com.br/futebol/copa-2014/videos/pepe-relembra-historia-da-copa-de-1958-com-garrincha-eradio,7461453.html.\%20Acessado\%20em\%2009/08/2015. Acessado em: 05/06/2017.

5) O vídeo com a versão da "história do rádio" que Pelé narra em uma entrevista no Programa do Jô, da Rede Globo, está disponível em: http://gshow.globo.com/programas/programa-do-jo/OPrograma/noticia/2014/09/reveja-pele-conta-historia-de-bastidor-da-selecao-brasileira-com-garrincha.html. Acessado em: 05/06/2017.

6) Deve-se destacar que Castro aponta a proximidade entre Garrincha e Sandro Moreyra para afirmar, pejorativamente, este jornalista como "responsável pela maioria das lendas sobre Garrincha" (CASTRO, 1995, p.96).

\section{REFERÊNCIAS}

ANDRADE, C. 2002. Quando é dia de futebol. Rio de Janeiro: Record.

CASTRO, R. 1995. A mentira tem pernas tortas. Placar, n. 1108, p. 94-97, outubro.

1996. Estrela Solitária: Um brasileiro chamado Garrincha. Rio de Janeiro:

Companhia das Letras.

FREITAS, G. 2014. Garrincha: O (anti-) herói pelo olhar dos cronistas. Em Tese, Belo Horizonte, v. 20, n. 1, p. 86-105, jan/abr.

GOODY, J.; WATT, I. 1963. The Consequences of Literacy. Comparative Studies in Society and History. Cambridge, vol. 5, n. 3, p. 304-345, abr.

GOODY, J. 2010. Myth, Ritual and the Oral. Cambridge: Cambridge University Press.

LEACH, E. 1970. Political Systems of Highland Burma: A Study of Kachin Social Structure. Londres: Athlone Press.

LEITE LOPES, J; MARESCA, S. 1992. A morte da "alegria do povo". Revista Brasileira de Ciências Sociais, n. 20, ano 7, p. 113-134.

MATTEUCCI, H. 1986. Memórias de Mário Américo: O Massagista dos Reis. $2^{\mathrm{a}}$ edição. São Paulo: Companhia Editora Nacional.

MOREYRA, S. 1998. Histórias de Futebol. Rio de Janeiro: Editora O Dia.

SANTOS, N. 1998. Minha bola, minha vida. Rio de Janeiro: Editora Gryphus.

SOARES, A; BARTHOLO, T. 2009. Mané Garrincha como Síntese da Identidade do Futebol Brasileiro. Movimento, Porto Alegre, v. 15, n. 01, p. 169-191, jan/mar.

TRIGO, M. 2002. O Eterno Futebol. Brasília: Thesaurus.

VOGEL, A. 1982. O momento feliz: reflexões sobre o futebol e o ethos nacional. Esporte na sociedade: um ensaio sobre o futebol brasileiro. In DAMATTA, R. et al. Universo do futebol: esporte e sociedade brasileira. Rio de Janeiro: Pinakotheke, p.75-113. 
WISNIK, J. 2008. Veneno remédio: o futebol e o Brasil. São Paulo: Companhia das Letras. 